\title{
ВЛИЯНИЕ СОСТАВА ВНЕШНЕЙ ТОРГОВЛИ РОССИЙСКОЙ ФЕДЕРАЦИИ НА СОЦИАЛЬНО-ЭКОНОМИЧЕСКИЕ ПОКАЗАТЕЛИ СТРАНЫ
}

\author{
(c) 2019 Бахарев Владимир Васильевич \\ кандидат экономических наук, доцент, Высшая школа сервиса и торговли \\ Санкт-Петербургский политехнический университет Петра Великого (СПбПУ), \\ Россия, Санкт-Петербург \\ E-mail: baharev_vv@spbstu.ru \\ (c) 2019 Конников Евгений Александрович \\ Высшая инженерно-экономическая школа \\ Санкт-Петербургский политехнический университет Петра Великого (СПбПУ), \\ Россия, Санкт-Петербург \\ E-mail: konnikov.evgeniy@gmail.com \\ (C) 2019 Конникова Ольга Анатольевна \\ кандидат экономических наук, кафедра маркетинга \\ Санкт-Петербургский государственный экономический университет, Россия, Санкт-Петербург \\ E-mail: olga.a.konnikova@gmail.com \\ (c) 2019 Лукашевич Никита Сергеевич \\ кандидат экономических наук, доцент, Высшая школа управления и бизнеса \\ Санкт-Петербургский политехнический университет Петра Великого (СПбПУ), \\ Россия, Санкт-Петербург \\ E-mail: lukashevich@kafedrapik.ru
}

На современном этапе развития одним из наиболее значимых драйверов экономического роста является внешняя торговля. При этом, чем больше страна интегрирована во внешнеторговый оборот, тем большее ее развитие начинает зависеть от соотношения экспорта и импорта отдельных групп товаров. В рамках данной статьи авторы исследуют вопрос зависимости ключевых социальноэкономических показателей России от динамики внешней торговли, в разрезе ключевых товарных групп.

Ключевые слова: внешняя торговля, промышленность, социально-экономические показатели.

На данном этапе развития России как никогда необходимо осознавать важность торговых отношений с внешним миром, т.к. это может повлиять не только на экономическую ситуацию, но и политическую обстановку в мире. На данный момент на федеральном уровне необходимо определить вектор развития на ближайшие годы для того, чтобы улучшить качество жизни собственного населения, а также прирастить свои экономические показатели. В связи с этом необходимо оценить вклад различных отраслей в развитие основных социально-экономических показателей. Таким образом целью работы является идентификация ключевых элементов внешней торговли России с точки зрения их влияния на социально-экономическое развитие страны, и формирование рекомендаций по раз- витию ключевых отраслей.

Данный вопрос рассматривался многими исследователями. В своей статье «Современное состояние внешнеторговой деятельности Российской Федерации» [1] Махмудова М.М. и Королева А.М. пишут о том, что в современных условиях внешнеэкономическая деятельность является важнейшим показателем вовлеченности страны в мировую экономику и международное разделение труда. Изучение влияния внешнеэкономической деятельности на социально- экономическое развитие государства позволяет определить ее высокую значимость. Изменение факторов политического и экономического характера: девальвация национальной валюты, станционная политика западных партнеров, падение цен на нефть - актуализирова- 
ло необходимость анализа динамики показателей внешнеторговой деятельности Российской Федерации. Были систематизированы основные теоретические подходы к обоснованию участия государства в мировых хозяйственных отношениях, начиная с позиции меркантилистов и классиков политической экономии и заканчивая современной теорией конкурентных преимуществ, сформулированной М. Портером. Представлены основные теории вовлеченности страны в мировую торговлю и рассмотрена необходимость проведения целенаправленной государственной политики в этой сфере. Проведен анализ внешнеэкономических связей России на современном этапе. В данной статье описаны значимые выводы, о том что Россия является активным участником микрохозяйственных торговых отношений и в современный условиях макроэкономической нестабильности, трансформации международных отношений. Однако в динамике внешнеторгового оборота страны наметилась неблагоприятная тенденция снижения объёмной внешней торговли.

В статье Тарасовой Т.Ф. и Тедеевой Р.А. «Влияние конъюнктуры потребительского рынка на уровень жизни населения Российской Федерации» [2] рассматриваются отдельные индикаторы потребительского рынка и их влияние на уровень жизни населения в сложившейся в настоящее время экономической ситуации. Целью данного исследования является определение степени влияния конъюнктуры потребительского рынка на уровень жизни населения, выявление взаимосвязи показателей конъюнктуры потребительского рынка и уровня жизни населения страны. В исследовании использованы общенаучные аналитические, графические и экономико-математические методы исследования, сравнительный, динамический и корреляционный анализ, что, в свою очередь, позволило представить и проанализировать динамику основных социально - экономических показателей потребительского рынка и уровня жизни, показать взаимосвязь понятий «уровень жизни» и «потребительский рынок». В статье приведены результаты анализа динамики торговли, по потребительским ожиданиям и намерениям населения Российской Федерации за исследуемый период. Авторы солидарны с тем, что высокая инфляция и стагнация номинальных зарплат не способствуют покупательной способности рос- сиян, усиливая их чувствительность к колебаниям цен.

Целью работы Путивцевой Н.П., Бугаева Д. С., Зайцевой Т.В. и Иргуновой С.В. «Прогнозирование внешней торговли России на основе метода анализа иерархий» [3] является разработка более достоверной модели прогнозирования внешней торговли России, которая позволяла бы осуществлять прогноз социально-экономических процессов на более длительный период, охватывать возможные варианты исхода и сценарии будущего развития внешней торговли России, выбирать наиболее подходящие сценарии, учитывать различную степень влияния критериев на фокус (цель). Также модель учитывает наличие акторов, неодинаковость их целей и степень их влияния на факторы. При проведении работы использовался модифицированный метод Саати, который позволил представить проблему разработки модели прогнозирования внешней торговли России в виде иерархии, реализовать иерархическую процедуру парных сравнений для выбора наилучшего сценария дальнейшего развития внешней торговли России, учитывающую влияние факторов, акторов, и получить итоговые оценки (веса) параметров обобщенного сценария. В результате получен прогноз экономических показателей на 2020-2025 года и дана их экономическая интерпретация. Результаты могут быть использованы для эффективного управления внешней торговлей. Данная статья отражает современные реалии экономики России.

В своей работе «Внешние угрозы экономике России» [4] Казанцев С.В. пишет, что экономическое положение в Российской Федерации и ее регионах в 2014 г. складывалось под воздействием неблагоприятной геополитической ситуации, ухудшающейся конъюнктуры мировых товарных рынков, введенных правительствами ряда стран санкций в отношении России и экономического спада внутри страны. В данной статье дается оценка потенциальной опасности негативных воздействий вышеназванных факторов. Исходной информацией для такой оценки служат показатели 2013 г.: величина оборота внешней торговли России со странами дальнего зарубежья; данные о поступлении в страну прямых иностранных инвестиций и о размере задолженности по кредитам, предоставленным кредитными организациями юридическим ли- 
цам; объемы средств, выплачиваемых за год за импорт технологий и услуг технического характера. На основе фактических данных о значениях этих показателей и о величине сальдированного финансового результата деятельности организаций в 2014 г. делается оценка реального ущерба, нанесенного субъектам Российской Федерации сжатием мировых товарных рынков и антироссийскими санкциями. Показано, что под влиянием названных и ряда других факторов социально-экономическое развитие части российских регионов замедлилось, экономическое положение части регионов ухудшилось. Выполненные расчеты показали, что сила влияния экономического спада в России, ухудшения конъюнктуры на мировых товарных рынках и введенных против Российской Федерации финансово-экономических санкций на изменение совокупности анализируемых показателей в российских регионах прямо пропорциональна зависимости хозяйствующих субъектов от иностранного капитала, внешних источников финансирования и внешнеторгового оборота. Выявлены субъекты Федерации, наиболее и наименее зависимые от этих факторов. Авторы солидарны с тем, что неблагоприятная геополитическая обстановка, сжатие мировых товарных рынков и действующие с марта 2014 года, расширяемые и «уточняемые» антироссийские санкции ограничивают возможности социальноэкономического и научно-технического развития России.

В статье «Инновационный механизм развития экономики европейского союза» [5] за авторством Смирнова Е.Н. проанализированы проблемы инновационного механизма развития экономики Европейского союза. Выявлена роль ведущих стран в повышении конкурентоспособности его экономики на основе инноваций и приоритеты посткризисного инновационного развития экономики ЕС. Обозначены инновационные приоритеты развития промышленной политики ЕС и показана роль внешнеэкономических связей в инновационном развитии экономики региона. Особое внимание в издании уделено методологически аспектам интеграции российской экономики в систему современных мирохозяйственных связей на основе инноваций. В частности, предложены пути повышения конкурентоспособности инновационной сферы России и оценены возможности реализации приоритетов инновационной модернизации национальной экономики с позиций использования опыта ЕС и задач эффективного построения межгосударственного инновационного пространства стран Евразийского экономического союза.

В рамках данных работ, а также многих других, предлагались факторы, как оказывающие влияние на социально-экономическое развитие России, так и отражающие ее. Для целей данного исследования обозначенные показатели агрегированы и распределены в соответствии с направлением влияния. В качестве эндогенных показателей были выбраны социально-экономические показатели, характеризующие уровень жизни россиянина:

1. $\mathrm{Y}_{\mathrm{t}}-$ Средняя заработная плата, руб.

2. $\mathrm{Y}^{2} \mathrm{t}-$ Минимальный размер оплаты труда (МРОТ), руб.

3. $\mathrm{Y}_{\mathrm{t}}-$ Прожиточный минимум, руб.

4. $\mathrm{Y}_{\mathrm{t}}-$ Заболеваемость, тыс. чел.

5. $\mathrm{Y}^{5} \mathrm{t}-$ ВВП на душу населения, дол.

6. $\mathrm{Y}_{\mathrm{t}}-$ Индекс развития человеческого потенциала, пункты

В качестве экзогенных показателей были выбраны крупнейшие статьи экспорта и импорта России:

1. $\mathrm{x}_{\mathrm{t}}-$ Общий экспорт из РФ за исключением общий импорт в РФ, млрд.дол.

2. $\mathrm{x}_{\mathrm{t}}-$ Экспорт из РФ минеральных продуктов за исключением импорта в РФ минеральных продуктов, млрд.дол.

3. $\mathrm{x}_{\mathrm{t}}-$ Экспорт из РФ металлов, драгоценных камней и изделий из них за исключением импорта в РФ металлов, драгоценных камней и изделий из них, млрд.дол.

4. $\mathrm{x}_{\mathrm{t}}-$ Экспорт из РФ машин, оборудования и транспортных средств за исключением импорта в РФ машин, оборудования и транспортных средств, млрд.дол.

5. $\mathrm{x}_{\mathrm{t}}-$ Экспорт из РФ продукции химической промышленности, каучука за исключением импорта в РФ продукции химической промышленности, каучука, млрд.дол.

6. $\mathrm{x}^{6} \mathrm{t}-$ Экспорт из РФ продовольственных товаров и сельскохозяйственного сырья (кроме текстильного) за исключением импорта в РФ продовольственных товаров и сельскохозяйственного сырья (кроме текстильного), млрд.дол.

7. $\mathrm{x}_{\mathrm{t}}-$ Экспорт из РФ древесины и целлюлозно-бумажных изделий за исключе- 
нием импорта в РФ древесины и целлюлознобумажных изделий, млрд.дол.

8. $\mathrm{x}_{\mathrm{t}}-$ Экспорт из РФ текстиля, текстильных изделий и обуви за исключением импорта в РФ текстиля, текстильных изделий и обуви, млрд.дол.

9. $\mathrm{x}_{\mathrm{t}}-$ Экспорт из РФ кожевенного сырья, пушнины и изделий из них за исключением импорта в РФ кожевенного сырья, пушнины и изделий из них, млрд.дол.

В первую очередь были исключены следующие эндогенные показатели в связи с недостаточным значением нормированного $\mathrm{R}^{2}$ :

1. $\mathrm{Y}_{\mathrm{t}}-$ Минимальный размер оплаты труда (МРОТ), нормированный $\mathrm{R}^{2}=0,61$

2. $\mathrm{Y}_{\mathrm{t}}-$ Заболеваемость, нормированный $\mathrm{R}^{2}=0,58$

3. $\mathrm{Y}_{\mathrm{t}}-$ Индекс развития человеческого потенциала, нормированный $\mathrm{R}^{2}=0,09$

Автокорреляционный анализ продемонстрировал следующее:

1. $\mathrm{Y}_{\mathrm{t}}-\mathrm{BBП} \mathrm{на} \mathrm{душу} \mathrm{населения} \mathrm{-} \mathrm{анализ}$ не показал зависимости изменения экзогенных показателей от времени.

2. $\mathrm{Y}_{\mathrm{t}}-$ Средняя заработная плата - автокорреляционный анализ показал наличие у каждой экзогенной зависимость от эндогенной с временным лагом в 2 года.

3. $\mathrm{Y}_{\mathrm{t}}-$ Прожиточный минимум - анализ показал наличие у каждой экзогенной зависимость от эндогенной с временным лагом в 3 года.

В результате были определены показатели, оказывающие наибольшее влияние на социально-экономические показатели. Рассмотрим последовательно полученные регрессионные уравнения. На рисунке 1 приведена динамика фактических и теоретических значений ВВП на душу населения.

Как видно на графике, теоретические значения стремятся к фактическим, отсутствуют значимые отклонения и структурные разрывы. Влияние экзогенных переменных на формализовано посредствам следующего регрессионного уравнения:

$$
Y_{5}=327,0459+0,01372 * x_{2}+(-0,02278) * x_{4}+
$$
$0,12631 * x_{7}+(-0,72665) * x_{9}$

Влияние каждого фактора может быть эффективно продемонстрировано посредствам коэффициента эластичности:

1. Влияние экспорта из РФ минеральных продуктов за исключением импорта в РФ минеральных продуктов - 34,72\%;

2. Влияние экспорта из РФ машин, оборудования и транспортных средств за исключением импорта в РФ машин, оборудования и транспортных средств - 17,20\%;

3. Влияние экспорта из РФ древесины и целлюлозно-бумажных изделий за исключением импорта в РФ древесины и целлюлознобумажных изделий $-7,56 \%$;

4. Влияние экспорта из РФ кожевенного сырья, пушнины и изделий из них за исключением импорта в РФ кожевенного сырья, пушнины и изделий из них $-35,92 \%$.

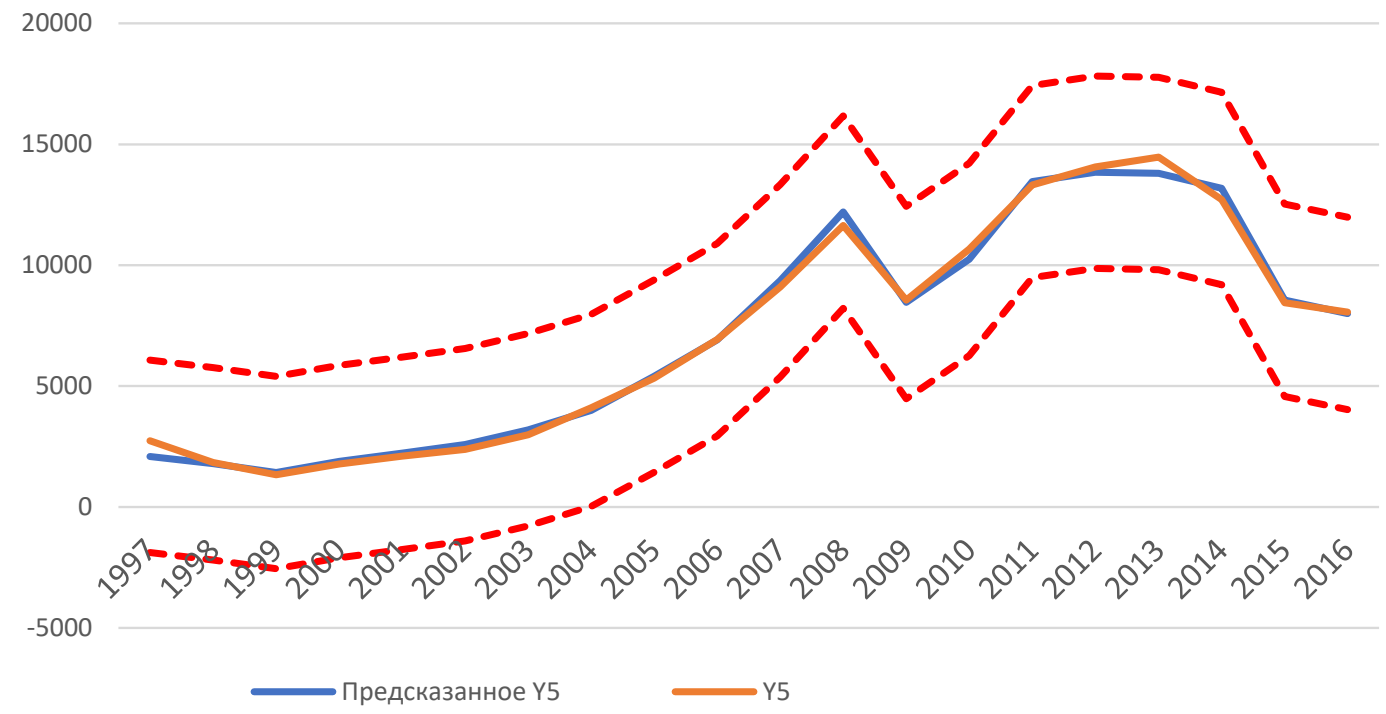

Рис. 1. Динамика фактических и теоретических значений ВВП на душу населения 
На рисунке 2 приведена динамика фактических и теоретических значений средней заработной платы.

Как видно на графике, теоретические значения стремятся к фактическим, отсутствуют значимые отклонения и структурные разрывы. Регрессионное уравнение имеет следующий вид:

$$
Y_{1}=2004,5963+(-0,48075) * x_{6}+1,526253 * x_{7}
$$

Таким образом, коэффициенты эластичности примут следующий вид:

1. Влияние экспорта из РФ продовольственных товаров и сельскохозяйственного сырья (кроме текстильного) за исключением импорта в РФ продовольственных товаров и сельскохозяйственного сырья (кроме текстильного) $-43,92 \%$.

2. Влияние экспорта из РФ древесины и целлюлозно-бумажных изделий за исключением импорта в РФ древесины и целлюлознобумажных изделий $-44,52 \%$.

В завершении рассмотрим влияние соответствующих экзогенных показателей на прожиточный минимум. На рисунке 3 приведена динамика фактических и теоретических значений прожиточного минимума.

Как видно на графике, теоретические значе-

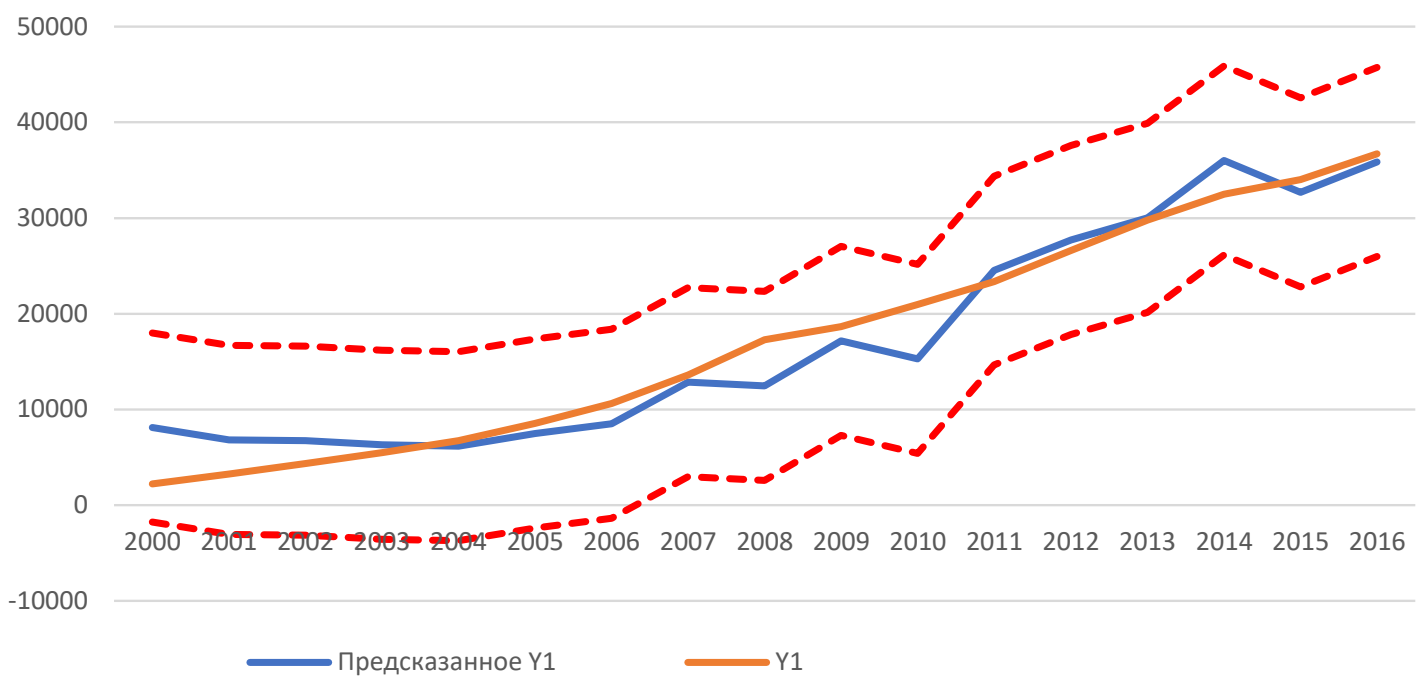

Рис. 2. Динамика фактических и теоретических значений средней заработной платы

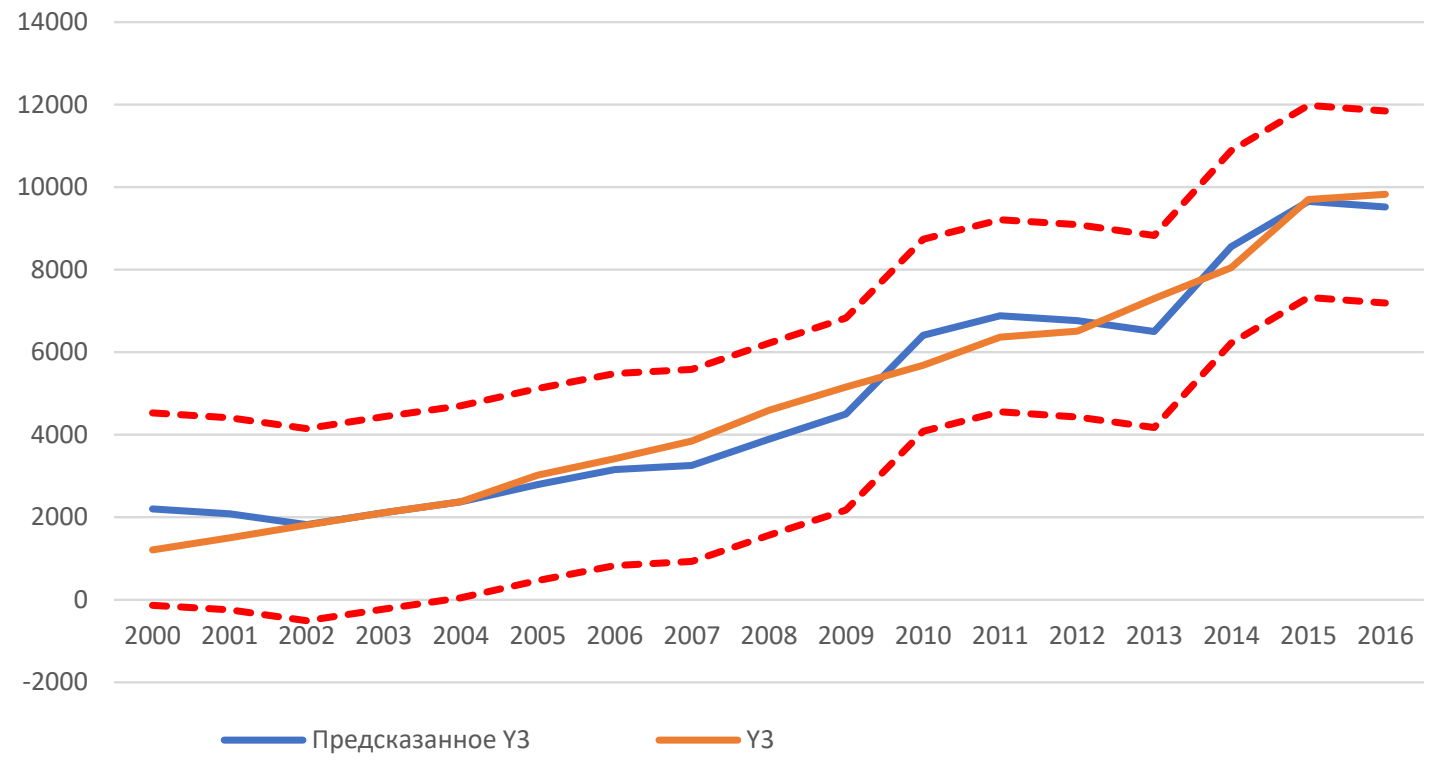

Рис. 3. Динамика фактических и теоретических значений прожиточного минимума 
ния стремятся к фактическим, отсутствуют значимые отклонения и структурные разрывы. Регрессионное уравнение имеет следующий вид:

$$
Y_{3}=1216,5687+0,39791 * x_{7}+(-0,74261) * x_{9}
$$

Таким образом, коэффициенты эластичности примут следующий вид:

3. Влияние экспорта из РФ древесины и целлюлозно-бумажных изделий за исключением импорта в РФ древесины и целлюлознобумажных изделий - 22,21\%.

4. Влияние экспорта из РФ кожевенного сырья, пушнины и изделий из них за исключением импорта в РФ кожевенного сырья, пушнины и изделий из них - 52,72\%.

В результате проведённых исследований можно сделать вывод, что на ВВП на душу населения России наибольшее влияние оказывает развитие рынка 4 основными группами товаров, это - минеральные продукты, машины, оборудование и транспортные средства, древесина и целлюлозно-бумажные изделия, а также кожевенное сырье, пушнина и изделия из них, причём преобладание импорта над экспортом в торговле машинами и оборудованием, а также превышение импортом экспорта кожевенного сырья влияют на развитие ВВП отрицательно, о чём говорят отрицательные коэффициенты регрессии в уравнении модели множественной регрессии. Активный экспорт минеральных продуктов и древесины, однако, показал положительное влияние на развитие ВВП на душу населения, что неудивительно, так как экспорт минерального сырья из страны, в частности нефти и нефтепродуктов, составляет значительную часть общего экспорта России, а торговля древесиной, несмотря на небольшой процент от общего экспорта, является, тем не менее, значимой, благодаря высокому качеству российской древесины. Таким образом, можно говорить о том, что на ВВП на душу населения в наиболее сильной степени влияют отрасли по добыче и использованию природного сырья, что характеризует экономику страны не с лучшей стороны, так как такая ситуация в основном присуща странам третьего мира. Так как природные ресурсы ограничены, правительству необходимо уже сейчас искать альтернативные отрасли, которые будут развиваться, обеспечивая России экономическую и политическую стабильность.

На среднюю заработную плату влияет в большей степени развитие рынков следующих групп товаров: продовольственных товаров и сельскохозяйственного сырья (кроме текстильного), древесины и целлюлозно-бумажных изделий. Стоит отметить, что это низкотехнологичные отрасли промышленности, то есть отрасли, в которых практически отсутствует генерация инноваций, которые не требуют затрат на новые разработки, и в которых основной ресурс - это трудовой ресурс, и именно они оказывают наибольшее влияние на изменение средней заработной платы. Также следует обратить внимание, что в конечном уравнении нет торговли минеральными продуктами, то есть, активный экспорт нефти не оказывает никакого влияния на изменение средней заработной платы россиянина, то есть никак не увеличивает его благосостояние или уровень жизни. Стоит заметить, что, судя по коэффициентам регрессии, превышение импорта продовольствия над экспортом оказывает отрицательное влияние на динамику средней заработной платы, то есть, чтобы увеличивать среднедушевой доход, необходимо расширять и развивать как пищевую промышленность, так и сельское хозяйство.

На прожиточный минимум влияет в большей степени торговля следующими товарами: древесиной и целлюлозно-бумажными изделиями, кожевенным сырьем, пушниной и изделиями из них. В данном случае можно сделать такие же выводы, как и в предыдущем, а именно: низкотехнологичные отросли промышленности имеют ключевое значение для увеличения прожиточного минимума. Как и в предыдущем случае, на прожиточный минимум не влияет экспорт минеральными продуктами, то есть вывоз заграницу нефти не улучшает благосостояние граждан. Как и в модели для ВВП на душу населения, превышение импорта кожевенного сырья и изделий из него имеет отрицательное влияние на эндогенную, прожиточный минимум. Из этого следует, что для улучшения уровня жизни государству необходимо развивать собственное производство кожи и древесины. 


\section{Библиографический список}

1. Махмудова М.М., Королева А.М. Современное состояние внешнеторговой деятельности российской федерации // Вестник Омского университета. Серия: Экономика. 2016. № 3;

2. Тарасова Т.Ф., Тедеева Р.А., Зиннатова Э.И. Влияние конъюнктуры потребительского рынка на уровень жизни населения Российской Федерации // Вестник Белгородского университета кооперации, экономики и права. 2017. № 1 (62);

3. Путивцева Н.П., Бугаев Д.С., Зайцева Т.В., Игрунова С.В. Прогнозирование внешней торговли России на основе метода анализа иерархий // В мире научных открытий. 2013. № 2-1 (38);

4. Казанцев С.В. Внешние угрозы экономике России // Мир новой экономики. 2016. № 2;

5. Смирнов Е.Н. Инновационный механизм развития экономики европейского союза // Москва, 2015;

6. Клочков Ю.С., Конников Е.А. Трансформация структуры производственной себестоимости на промышленном предприятии в процессе интеграции аддитивных технологий // Известия Самарского научного центра Российской академии наук. 2019. Т. 21. № 1. С. 5-10;

7. Конников Е.А., Конникова О.А., Лукашевич Н. С. Векторная модель оценки потенциальной результативности решений, направленных на повышение устойчивости развития промышленного предприятия // Экономические науки. 2019. № 170. С. 47-50;

8. Конников Е.А., Белостоцкая А.А., Забелин Б. Ф. Показатели обеспеченности ресурсами как критерии оценки финансового состояния промышленного предприятия // Экономика и предпринимательство. 2015. № 12-1 (65). С. 771-776;

9. Конников Е.А., Барсков В.В. Цель российской промышленности и результаты ее достижения на современном этапе // Экономика и предпринимательство. 2015. № 11-2 (64). С. 167-170. 